\title{
Research on the Embodiment of Aesthetic and Practice Education in Piano Teaching
}

\author{
Xuyan Wang 1 , a \\ ${ }^{1}$ Teacher's College, Beihua University, Jilin 132013, China. \\ axuyan_wang@126.com
}

Keywords: Piano teaching; aesthetic and practical education; higher vocational colleges.

\begin{abstract}
The aesthetic and practical education which is a new educational philosophy based on application-oriented personnel training was selected for piano teaching in higher vocational colleges. In this paper, the main purpose is to build an embedded piano teaching play platform, study how to advance music education and especially develop of piano teaching, and develop media on this condition.
\end{abstract}

\section{Introduction}

The beauty of music is particularly musical in nature, and this beauty comes from a combination of the internal sounds of music. It is the various relationships and interactions between sounds that provide an aesthetic experience that is different from other experiences. For "formalists," this is undoubtedly the music "form" affirmation, but this does not mean that they give up the influence of the external world. Extreme formalism, represented by Hanslick, is over, and as long as it ensures that the "inner" concern for music, the influence of "externality" can also be considered. But how to balance the relationship between the two is a problem. In fact, this issue is in the "aesthetic" in the "aesthetic" grasp of a consideration.

First of all, music in the "beauty" and the real world "beauty" is different, because the former has a "musical". Therefore, grasping the "beauty" in music is the essence of aesthetic experience. Secondly, the "beauty" in the music is influenced by the external influence, which has the meaning of "beauty" in the real world. Lucy Greene calls it "depicting the meaning". This "depiction of meaning" is a necessary complement to the "beauty" of music. It is with this "depicting the meaning of" music is not for music and music. In other words, music is not only those so-called music "beauty" musicians enjoy "rights". Music is not the so-called "elitism" packaged under the political product or cultural monopoly. Music is perceived and experienced by anyone, although many people perceive it from the added value that music has given to it, but this does not affect people's learning about the "form" of music and the " Beauty "of the re-excavation. Once again, people have the "music aesthetic" the basic conditions. In addition to the experience of "portraying meaning", there is a perception of "beauty" in music. This experience is derived from the perception of a sound as the basic material of music.

After clarifying the object of "Aesthetic Appreciation of Music", the purpose of how to reach "Aesthetic" is discussed here. Sound is the basic element of music composition, as the form of music, its specific form is the specific composition of the various sounds of music. Sound is the existence of matter, and therefore can be experienced. Therefore, the "experience" is the aesthetic way of music. "Experience" is resorted to the senses, and sensory is the way leading to the inner world. Is the relative presence of the external world involved through action. There are two worlds, the inner world and the outer world. This music and the two are in line with the United States. "Beauty" in the music must be "experienced" by the inner world, "aesthetic" will occur. In other words, the only way to discover "beauty" in music is to "experience". However, the role of "experience" is not a single point to music in the "aesthetic", "experience" is also involved in the exchange of the outside world and the reality of the United States found. Therefore, "experience" is a multi-latitude, but in the "aesthetic music" is unique. Therefore, concerned about the material nature of music is the primary task of 
music education. But music also has a "portrayal of meaning", which also means that other "non-musical" factors for the music experience also has varying degrees of impact.

Feeling experience is based on the relationship between emotion, feeling, and music. Feeling is not emotion, it is the emotional level of an expression and logical thinking of the opposite. However, emotion and feeling are linked. "Sensation is the 'release' of the actual experience of the body experiencing emotionally, in which" release "is also conscious. That is to say that people consciously release their experience of some kind of emotion. The source of emotion is diverse, if music as a source of emotion, people are aware of this at the same time feel the emotion, so as to further promote their own understanding of music. This is one of the most important effects of sensory experience on music.

From this perspective, music education is the sense of education. In the sense of education need to pay attention to two issues, namely, as the subject of sensory and sensory objects as the music. The former individual differences lead to a different degree of sensory music, the nature of the latter also determines the way the sensory experience. First of all, the way this experience is direct, which is the subject from the heart of the purpose of cognitive music; Second, this direct experience is not entirely rely on the interpretation of a symbol can be achieved. Therefore, in the sense of education, it is necessary to avoid entirely rely on the association caused by the feeling should also be completely ruled out to avoid the significance of association. To derive a reasonable interest in the ability of music to mediate and its relevance.

\section{The Role of Practice in Music Education}

It is the result of David Elliot's reflection on the aesthetic education that transforms the music perspective from the work into the activity. As he said: "Fundamentally, music is a human thing." Music is a human purposeful activity. Therefore, this process includes three aspects of the act, namely, creators, creative activities and works. The three require a specific context when they become a purposeful activity. Therefore, context becomes the fourth dimension of music. Music practice in different contexts is also different, that is to say, music is a diversified human practice. This practice is not only for the music itself, the more is the music behavior and activities reflect the social culture and meaning. This idea of placing music in the context of multiple factors is inspired by the development of contemporary multiculturalism, in particular the influence of cultural relativism. Music from the composition of the cultural context of music often contains economic, political, religious, historical and other factors. Music can not be isolated from these contents. Emphasis on multiculturalism is the recognition of the existence of individuals in the complex and changeable links, but also there is a specific context. Only in a more independent cultural context to establish mutual respect for the interpretation of music culture context, and through mutual exchange and interaction can be achieved for the individual interpretation and transcendence. The interpretation of music in this way can show respect for the independence and diversity of individuals in different contexts. Music can be a comprehensive and objective to achieve and interpret.

In essence, music production is procedural knowledge of things. In addition, music production is also affected by other different music knowledge: regular music knowledge, informal music knowledge, impression music knowledge, instructional music knowledge. These music knowledge together constitute the people in music production reflects a variety of cognitive forms that music literacy. Music quality determines the level of people in dealing with music knowledge and practice of music-related sound model. So why can music literacy achieve the dominant function of music? First of all, the language can not effectively achieve its guidance in music performance practice. From another point of view, music practice and the production of music knowledge with "simultaneity" characteristics. It also means that when people sing or play, the perception of music exists in the purpose of this act. This "contemporaneous" musical thought can not be expressed in a certain language before the practice of music. People can not pre-set all the steps to conduct music acts, but only according to an abstract, general concepts, rules for guidance. Therefore, "a person 's 
performance of a given work is his (her) music practice and its musical understanding of the musical works of a strong show.

Context is the fourth dimension of the concept of music as a practice. This also shows David Elliott's multi-angle observation of music, which exists in the interrelationship of the elements. First of all for the composition, the production of each piece of music is not individual behavior, they are a particular history, social and cultural products. So the creative power of music from the practice of music authority of the composer and performer's musical behavior and the development of musical thought. In addition, music creation needs to establish a different narrative structure to meet the needs of different musical genres. At the same time, the composer considers various problems in music practice to ensure the "feasibility" of the musical work. Second, for music performances, performers need to have a certain amount of professional music knowledge to meet the needs of playing. In addition, performers need to act as musicians and listeners communication medium, the musician's intention to convey to the audience. The audience is not only the recipient of the music, but also need to have the appropriate ability to appreciate music. This is also an important prerequisite for musical performances.

\section{Piano Teaching under Aesthetic Education}

The essence of aesthetic education is to equate the artistry of music with aesthetics. To the traditional Western aesthetic concepts as the basis for the aesthetic experience as a method to stimulate the aesthetic of the inner feelings. The purpose of aesthetic education is to enrich students' aesthetic experience and to improve their inherent music tasting ability. From the perspective of metaphysical philosophy of education, this paradigm of education has a clear goal, but from the specific physical level of operation in terms of different music education disciplines, the goal of directivity and orientation is required Adjusted. Especially in the piano teaching such performance disciplines, even more so. Piano teaching is the ultimate goal of aesthetic education as the standard, but to achieve this ultimate goal, piano teaching is mainly based on skills training. During this period, how to reflect the aesthetic paradigm of music education is the need to clarify and explore this issue.

\section{Piano Teaching in Practical Education}

Practice education that the music is not only exist as an aesthetic object, in addition to aesthetic music is also artistic. This kind of artistic mastery is the fundamental of music education. The "artistic" production is a "dynamic" process, which exists in the creator, works, performers and recipients of the relationship between them. At the same time, this relationship is also affected by the "current" impact. Therefore, the grasp of music has increased the dimension of a broader space. Of course, it is necessary to put music in a larger cultural and historical context. But for the teaching of piano, in the face of traditional forms of music - works is still the most basic. Then the practice of education for how to interpret the work.

Different from the music value emphasizing "aesthetic", the musical meaning in the perspective of multiculturalism is mainly embodied in two aspects, namely "directivity" and "embodiment". The former emphasizes not the music ontology, but the outside world for the function of music produced by the functional significance, with a symbolic. The latter is a manifestation of a logical relationship, with some kind of predictive. Then the context of musical meaning is the style. To a large extent, the generation of style also depends on the two aspects of the culture of the times and the psychological mechanism of the recipient. Different times, different forms of music culture language such as tone, scale, melody, etc., thus forming a different musical style. But whether the recipient can fully understand these styles. Or the level and extent of their understanding is the psychological mechanism of the problem. In other words, once a style can be seen as a "probability system", the musical style into the inherent probability structure. As for the result and expectation in the probability, the musical meaning is embodied in the consciousness of probability of fact to individual choice. The probability of a particular style and the manner in which it is perceived by the style 
material form the "norm" of that style. How to make this kind of "norm" maximized to be perceived by people, you need music experience accumulation. This is also emphasized by "practical education".

The law of style change is not the "evolution" emphasized in Darwin's theory of evolution. This theory of deterministic nature has not worked in today's multicultural value system. As mentioned above, the creation of style is the establishment of the structure of the inherent language of music. Once established, that produces some kind of dynamic. The dynamics of the style itself is not isolated, but also depends on the complementary social conditions. Then the style of the composer is also a self-learning process. The interpretation of different musical styles needs to be realized through the depth and intensity of the previous style study and the inner order of the works. According to these two aspects of the relationship between the internal music style was able to distinguish between different stages. A style before the advent of a large number of composition techniques are often based. In the process of becoming more mature style of the internal structure and technical methods of interaction, and ultimately achieve a balance. In the multicultural context, the external social conditions for the internal structure of the balance of the order was once again broken. Need to see is that the internal order of music style as the basis of the existence of the style of the value of the music itself will continue to build, but the impact of external culture has increasingly become a new factor in the formation of decision style.

\section{Conclusion}

Aesthetic education and practical education are two popular philosophical ideas in music education. In this paper, the piano teaching in music education as a starting point to observe the "aesthetic education" and "practical education" in the specific embodiment of music education. The conclusions of this paper are summarized as follows:

The differences between aesthetic education and practical education in piano teaching are mainly reflected in the following aspects: First, the difference of teaching works. The foundation of the formation of aesthetic education paradigm determines the face of the works can only be traditional Western art music. Because modern music, especially popular music is not a type of music, more inclined to social and cultural activities. Therefore, the traditional music aesthetic education is unable to accurately interpret its intrinsic meaning and value. Second, the analysis of the works of different dimensions. Aesthetic Education is the Prerequisite of Careful Works. Therefore, the analysis and interpretation of the works is only limited to this single point. Practical education, from different "context" to change the observer and the observer of the relationship between subject and object to emphasize the non-traditional Western music works of independence and difference. Third, the musical value of the different emphases. The value of music in aesthetic education is mainly embodied in the aesthetic value of music works, and emphasizes the value of this value to the aesthetic feeling of learners.

\section{References}

[1] McMahon;Guan Jianhua, Qiao Xiaodong.Contemporary Music Education, Beijing: Culture and Art Publishing House, 1991.

[2] Carl Dahlhaus, Yang Yandi: Principles of Musical Historiography, Shanghai: Shanghai Conservatory of Music Publishing House, 2006.

[3] David Elliott; Qi Xue, Lai Dafu: "Paying Close Attention to Music Practice - New Music Education Philosophy", Shanghai: Shanghai Music Publishing House, 2009.

[4] "Music education philosophy" (third edition), Beijing: People's Music Publishing House, 2011.. 
[5] Luo Qin: "World Music Humanistic Narrative and Its Theoretical Basis", Shanghai: Shanghai Conservatory of Music Press, 2013. 